INDEPENDENT JOURNAL OF MANAGEMENT \& PRODUCTION (IJM\&P)

http://www.ijmp.jor.br

v. 12, n. 6, Special Edition ISE, S\&P - November 2021

ISSN: 2236-269X

DOI: 10.14807/ijmp.v12i6.1782

\title{
FORECASTING THE TIME STOCK FOR CHEMICAL PLANT PROTECTION BASED ON COMPUTER SIMULATIONS
}

Anatolii Tryhuba Lviv National Agrarian University, Ukraine E-mail:atryguba55@gmail.com

Inna Tryhuba Lviv National Agrarian University, Ukraine

E-mail:trinle@ukr.net

Larysa Mykhalchyshyna National University of Life and Environmental Sciences of Ukraine, Ukraine E-mail: larysamykhalchyshyna@ukr.net

Iryna Mushenyk State Agrarian and Engineering University in Podilya, Ukraine E-mail: mushenik77@ukr.net

Nonna Koval State Agrarian and Engineering University in Podilya, Ukraine E-mail: koval_nona89@i.ua

Yuliia Haybura IJTM\&E State Agrarian and Engineering University in Podilya, Ukraine E-mail: hayburay@gmail.com

Submission: 8/28/2021 Accept: 9/23/2021

\section{ABSTRACT}

The approach, algorithm, and intelligent system of support of decision-making of management for forecasting of time fund for the performance of the mechanized chemical protection of plants are offered. They are based on the formation of a database and knowledge of the weather from the Open Weather Map service for individual countries and their regions. They provide the formation of databases and knowledge for a given country or its region, taking into account the characteristics of natural, climatic, and industrial conditions based on computer modelling. Also, the proposed intelligent management decision support system provides a systematically accountable set of variable agrometeorological components of the 
DOI: 10.14807/ijmp.v12i6.1782

mechanized chemical plant protection system and their impact on the projected time fund of the relevant work. Based on the use of the developed intelligent system of support of acceptance of administrative decisions forecasting of time fund for the performance of the mechanized chemical protection of plants and the set natural-climatic and industrial conditions is executed. The climatically admissible time fund model for mechanized chemical protection of plants during the day for May, which is described by Weibull distribution, is substantiated. The obtained research results can be used by managers of agricultural enterprises during the management processes of forecasting the time fund for the implementation of mechanized chemical plant protection. The developed intelligent decision support system provides further research on forecasting the time fund for the implementation of mechanized chemical plant protection and substantiation of its models for different countries and their regions.

Keywords: forecasting, time fund, agrometeorological conditions, chemical protection, plants, intelligent system, management decisions.

\section{INTRODUCTION}

Agricultural enterprises engaged in crop production suffer annual losses and lose significant crop yields from weeds, pests, and diseases. According to the FAO (Food and Agriculture Organization), more than $40 \%$ of the world's crop is lost each year due to pests, including about 37\% before harvest and 9\% during storage. These losses from crop losses are estimated at \$ 30 billion. At the same time, due to diseases of agricultural plants, the losses amount to $\$ 25$ billion (Tryhuba et al., 2021a; Tryhuba et al., 2019a). To prevent and prevent crop losses from pests perform mechanized chemical plant protection. At the same time, the content and time of performance of works on mechanized chemical protection of plants are planned.

Qualitative planning of these processes can be performed only with a known time fund for the implementation of mechanized chemical plant protection (Tryhuba et al., 2021a; Tryhuba et al., 2019b). Forecasting the time fund for the implementation of mechanized chemical plant protection is a complex management task. This is due to the influence of many variables of the agrometeorological component on the performance of mechanized chemical protection of plants, which leads to time-consuming calculations based on the theory of probability and mathematical statistics (Tryhuba et al., 2021b; Ratushny et al., 2019). The above indicates a need to substantiate the peculiarities of forecasting the time fund for mechanized chemical plant protection, as well as due to the time-consuming calculations of 
DOI: 10.14807/ijmp.v12i6.1782

application software based on computer simulation of agrometeorological component mechanized chemical plant protection.

There is a need to develop an intelligent system to support management decisions. The main requirements for users of this system include: reliability, clear user interface, ensuring high-quality forecasting of the time for mechanized chemical protection of plants, taking into account the climatic and production conditions of a particular region.

\section{LITERATURE REVIEW}

Many works are devoted to the solution of problems of forecasting of time fund for the performance of works in various applied spheres taking into account their features (Tryhuba et al., 2021c; Hulida et al., 2019; Ratushny et al., 2018; Pavlikha et al., 2019; Bashynsky, 2019). They are based on the developed mathematical models and methods, which partially idealize and take into account the peculiarities of the production conditions of the subject area.

Some of the scientific publications (Fraisse et al., 2006; Roy et al., 2019; Boyarchuk et al., 2020; Syrotiuk et al., 2020) substantiate the need to develop universal tools for forecasting the time for work without taking into account the specifics of applications spheres. The authors of these scientific works propose to use models and methods that are based on traditional forecasting approaches that do not fully take into account the features of the agrometeorological component of the system of mechanized chemical plant protection.

Of particular note are existing publications (Tryhuba et al., 2021c; Bashynsky, 2019; Tryhuba et al., 2020a; Tryhuba et al., 2020b; Boyarchuk et al., 2019a; Boyarchuk et al., 2019b), which relate to forecasting in agricultural production. Some of them relate to crop production and take into account the specifics of this industry. However, it is impossible to use them in full to forecast the time fund for the implementation of mechanized chemical plant protection, as they do not take into account the features of the agrometeorological component of the system of mechanized chemical plant protection.

There are several scientific papers (Boyarchuk et al., 2019a; Ljaskovska et al., 2018; Boychenko et al., 2007), in which their authors take into account the peculiarities of the agrometeorological component for different systems of agricultural production. They are used in intelligent management decision support systems. However, as for taking into account the peculiarities of the agrometeorological component in intelligent decision support systems, they are absent for mechanized chemical plant protection. In particular, the existing intelligent 
DOI: 10.14807/ijmp.v12i6.1782

decision support systems are designed for strategic and tactical planning of work (Bashynsky et al., 2019; Serrano et al., 2004; Sokulskyi et al., 2020).

The task of operational forecasting of the time fund for the implementation of mechanized chemical plant protection requires consideration of natural, climatic, and production conditions of individual countries and their regions and appropriate research to ensure an adequate database and knowledge underlying the intelligent decision support system for fund forecasting time to perform mechanized chemical protection of plants under given conditions.

Thus, the existing approaches and intelligent decision support systems for planning in crop production do not fully take into account the changing climatic and production conditions of individual countries and their regions, which determine the time to implement mechanized chemical plant protection. This is one of the main reasons for making incorrect management decisions during the operational planning of mechanized chemical plant protection, as well as losses of cultivated agricultural products due to untimely reduction of pests and plant diseases.

Currently, there is a scientific and applied problem to substantiate the approach to forecasting the time fund for mechanized chemical plant protection, as well as due to the need for time-consuming calculations, development of application software based on computer modelling of agrometeorological component of mechanized chemical plant protection countries and their regions. The article confirming its scientific and practical value is devoted to the solution of this scientific and applied problem.

The aim of the work is to substantiate the approach to forecasting the time fund for mechanized chemical plant protection and on its basis to develop an algorithm and intelligent management support system based on computer simulation and provide high-quality forecasting of time fund for mechanized chemical plant protection. taking into account the peculiarities of the agrometeorological component of individual countries and their regions.

To achieve this goal should solve the following tasks:

- to propose an approach, algorithm, and intelligent support system for making management decisions to forecast the time fund for the implementation of mechanized chemical plant protection;

- on the basis of using the developed intelligent support system for making management decisions to forecast the time fund for mechanized chemical plant protection and given 
DOI: $10.14807 /$ ijmp.v12i6.1782

climatic and production conditions to justify the model of climatically acceptable time fund for mechanized chemical plant protection during the day.

\section{RESULTS AND DISCUSSIONS}

During the season of action of harmful objects on crops of separate crops, there are intervals of time during which it is possible or impossible to carry out mechanized chemical protection of plants. In view of this, the naturally determined time fund for the implementation of mechanized chemical protection of plants is the time (in hours) during which you can perform the technological operation of spraying crops.

The formation of a naturally acceptable time fund for the implementation of mechanized chemical plant protection is based on a number of climatic factors that reflect the meteorological conditions of a particular region:

$$
f_{T}^{X O}=f(O, R, V, T, I)
$$

where $\mathrm{O}$ - the presence of precipitation, $\mathrm{R}$ - the presence of dew; $\mathrm{V}$ - the wind speed; $\mathrm{T}$ - the air temperature; I - the time of day (light or dark).

Equation (1) is presented in an implicit form, since its disclosure is possible only on the basis of computer modeling of the implementation of mechanized chemical plant protection, taking into account the climatic and production conditions of a particular region. At the same time, the features of the implementation of mechanized chemical plant protection in certain regions are being revealed.

A feature of mechanized chemical protection of plants by spraying is their high sensitivity to weather conditions and the state of the surface layer of the atmosphere (Bazzaz et al., 1996; Lobell et al., 2007). Thus, rainy weather, fog, rising heat fluxes, wind are among the unfavorable conditions that can completely neutralize the efficiency of cultivation and cause negative environmental consequences. Adverse weather conditions significantly affect the rate of pesticide use and environmental friendliness of chemical plant protection processes.

When the wind speed is more than $4 \mathrm{~m} / \mathrm{s}$, the sprayed mixture of boom sprayers will wear out of the field, polluting the environment. At air temperatures above $+25^{\circ} \mathrm{C}$, the droplets of the working liquid evaporate quickly. With excessive humidity and precipitation, the working fluid is washed away from the plants, reducing the efficiency of cultivation and contaminating the soil. 
DOI: 10.14807/ijmp.v12i6.1782

It is known that in some countries there is a continuously changing state of the atmosphere, which is determined by the stochastic sequence of alternation of naturally acceptable and unacceptable time intervals for mechanized chemical plant protection in terms of a single calendar day $\left(\tau_{d}\right)$ and a specific calendar period (plant development phase) (Tryhuba et al., 2021a; Islam et al., 2017).

Determination of the natural allowable time fund for mechanized chemical protection of plants $f_{T}^{X O}$ is performed depending on the weather conditions and it can be graphically displayed on the calendar time axis of the time of onset and duration of individual agrometeorological factors both singly and in combination.

Obviously, the main role in the formation of a naturally acceptable time fund for mechanized chemical plant protection $f_{T}^{X O}$ is played by rainfall (short-term or long-term and its intensity), which determines the waiting time $\left(\tau_{\text {о }}\right)$ after its completion (time for drying soil and plants).

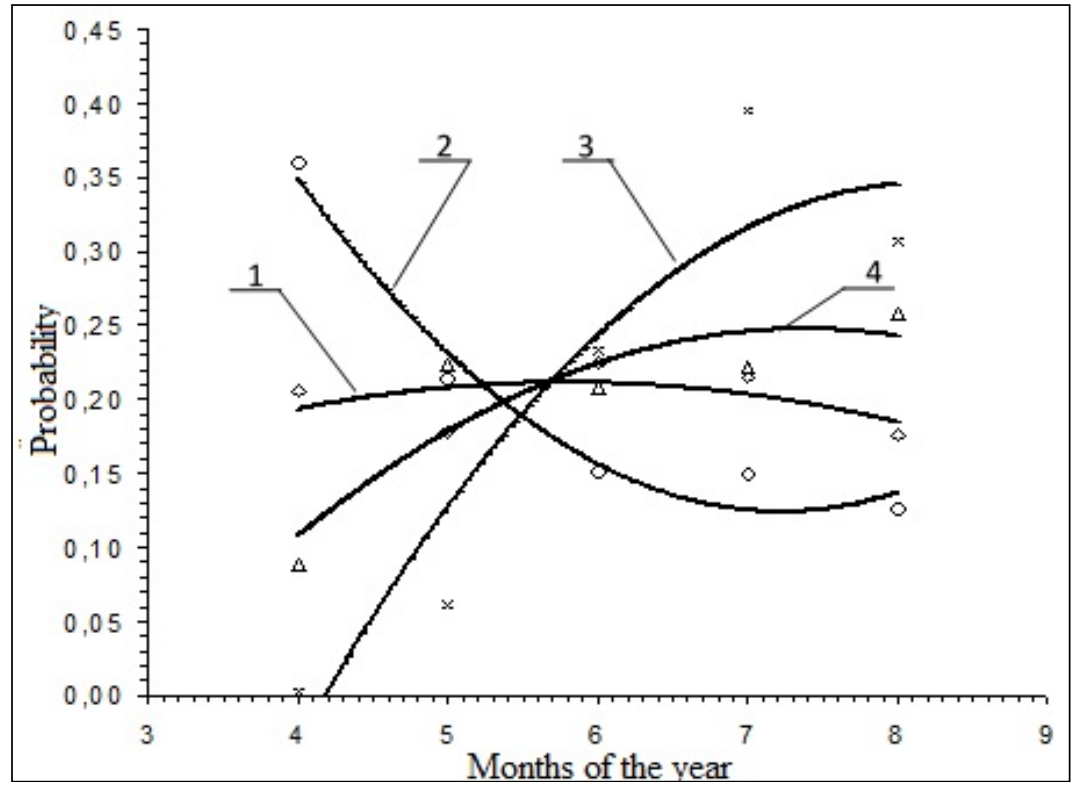

Figure 1: Dependence of the probability of occurrence of certain agrometeorological factors during the mechanized chemical protection from the calendar term (during April-August) for the conditions of the Western Forest-Steppe of Ukraine: 1 - the presence of precipitation; 2 excessive wind speed; 3 - above-average daily air temperature; 4 - the presence of dew

The effect of agrometeorological factors during the period of cultivation of crops (April-August) characterizes the probability (Boyarchuk et al., 2019): 
DOI: $10.14807 /$ ijmp.v12i6.1782

$$
P(A)=\frac{m_{A}}{n} .
$$

де $n$ - the total number of cases studied; $m_{\text {A }}$ - - the number of cases corresponding to a particular event $A$.

According to the statistics of the reporting period (April-August (Tryhuba et al., 2021a)) determined the number of events that met a certain condition (occurrence of excessive values of limiting factors) in a single calendar day to the total number of studied days. In nature, there are certain patterns, for example, if the dew falls, there is no rain, and vice versa, the time with excessive air temperature is monitored only in the middle of the day (when the sun is at its highest point relative to the horizon).

As the probability of the appearance of the maximum average daily air temperature due to the increase in the height of the sun above the horizon increases, the probability of occurrence of excessive permissible values of wind gusts decreases, although the probability of dew increases. On the other hand, it can be argued that precipitation slightly depends on other agrometeorological factors (average daily air temperature, dew, excessive wind gusts), as evidenced by the correlation coefficient (Table 1).

Table 1: Equations and correlation coefficients of the probability of occurrence of individual agrometeorological factors during the implementation of mechanized chemical protection of plants from the calendar term (April-August)

\begin{tabular}{|c|c|c|}
\hline Indicator & Equation & Correlation coefficient \\
\hline Wind & $P(A)=0.0217 m^{2}-0.3137 m+1.2569$ & 0,98 \\
\hline Dew & $P(A)=-0.0122 m^{2}+0.1797 m-0.4154$ & $-0,88$ \\
\hline Average daily air temperature & $P(A)=-0.0217 m^{2}+0.3549 m-1.1042$ & $-0,93$ \\
\hline Precipitation & $P(A)=-0.0055 m^{2}+0.0642 m+0.0253$ & $-0,5$ \\
\hline
\end{tabular}

Thus, the simultaneous consideration of many agrometeorological factors is quite difficult. However, without it, it is impossible to objectively justify an effective set of machines for chemical plant protection by spraying. The obtained regularities are the first step in the way of modelling the action of these factors and probabilistic estimation of the naturally allowed time fund for spraying plants.

The established patterns of occurrence and course in a time of certain agrometeorological factors are the first step towards the reflection of naturally determined time funds for the implementation of mechanized chemical protection of plants by spraying. It is 
DOI: 10.14807/ijmp.v12i6.1782

hypothesized that such agrometeorological factors as the average daily air temperature (correlation coefficient - 0.93), excessive allowable wind speed (correlation coefficient-0.98), and dew (correlation coefficient - 0.88) are dependent on the calendar time. Taking into account the peculiarities of agrometeorological conditions for a given region in the simulation model will allow us to objectively justify the need for technical means for the chemical protection of plants by spraying.

To forecast the time fund for the implementation of mechanized chemical plant protection, during which favorable weather conditions for the implementation of mechanized chemical plant protection by spraying perform the collection of weather statistics from the OpenWeatherMap service for individual countries or their regions.

Based on the above, the following conditions were considered favorable for the technological processes of chemical plant protection: air temperature $+5^{\circ} . .+25^{\circ} \mathrm{C}$; no precipitation and fog; wind speed $0 \ldots 4 \mathrm{~m} / \mathrm{s}$; absence of thermal ascending currents in the surface layer of the atmosphere.

The block diagram and algorithm for forecasting the climatically acceptable time fund for mechanized chemical protection of plants by spraying on a single day were developed on the basis of sound methods and models of characteristics of climatic and industrial conditions (Tryhuba et al., 2021a).

The block diagram consists of 19 blocks (Figure 2).

The first block is designed to store in the PC`s memory the initial data: the length of daylight; the presence of dew; air temperature; wind speed and precipitation.

Blocks 2-9 are designed to form agrometeorological numerical series and check the compliance of their values. 


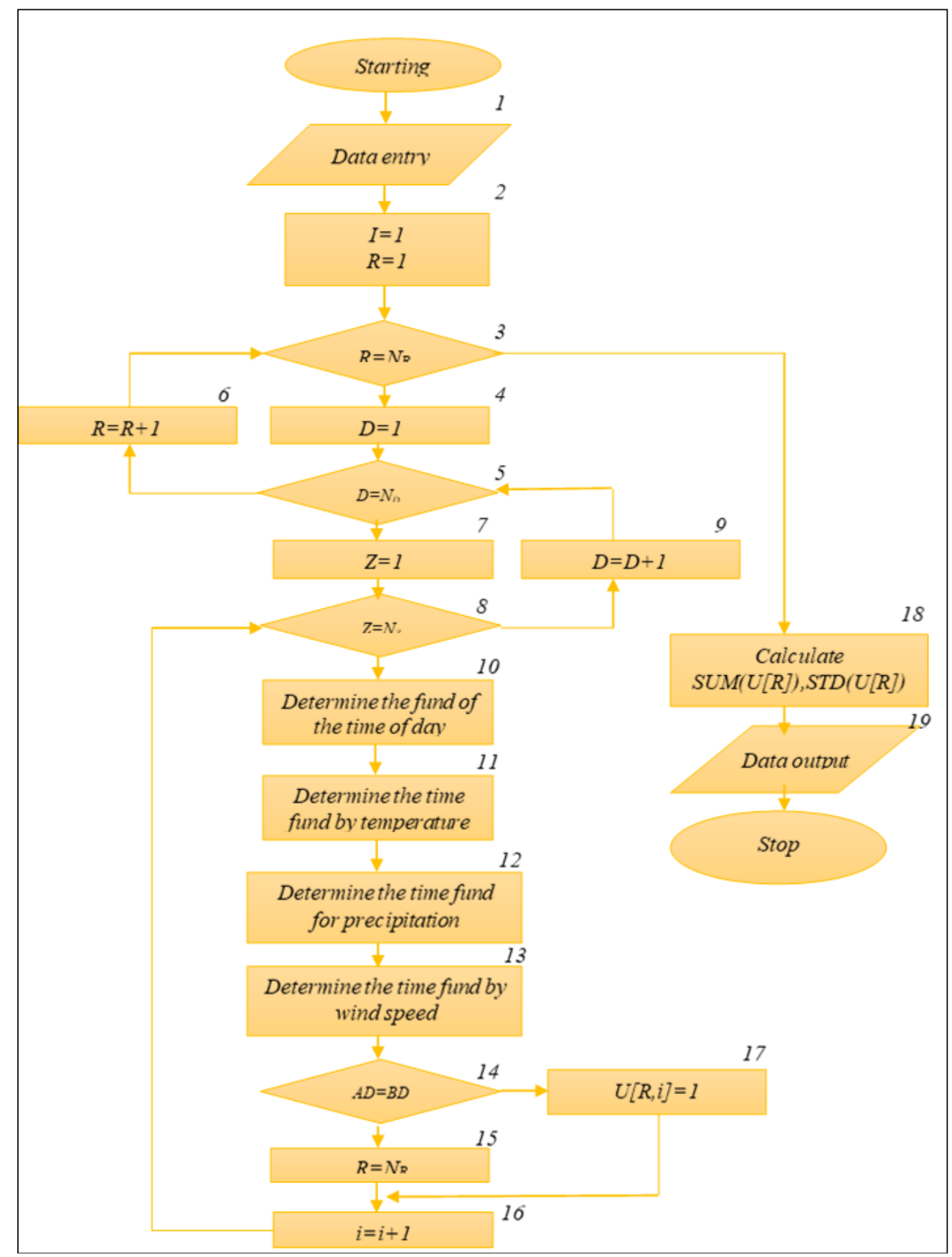

Figure 2: Block diagram of the algorithm of computer modelling of agrometeorological component and forecasting of climatically admissible fund of time for performance of the mechanized chemical protection of plants by spraying in a separate day

Blocks 10-13 are designed to determine the climatically acceptable time fund for the implementation of mechanized chemical protection of plants by spraying on a particular day, respectively, the length of daylight; the presence of dew; air temperature; wind speed, and precipitation.

Blocks 14-17 are designed to verify compliance with the values of the climatically acceptable time fund for the implementation of mechanized chemical protection of plants by spraying on a single day. 
DOI: 10.14807/ijmp.v12i6.1782

Block 18 is designed to check the condition of completeness of the implemented implementations and determine the climatically acceptable time fund for the implementation of mechanized chemical protection of plants by spraying on a single day.

Block 19 is designed to display the results of calculations.

Based on the disclosure of the content of the blocks depicted in the block diagram, an algorithm for computer modelling of agrometeorological component and forecasting the climatic time fund for mechanized chemical protection of plants by spraying on a single day and an intelligent management decision support system for forecasting the time fund mechanized chemical plant protection in Python 3.9, the working window of which is shown in Figure 3.

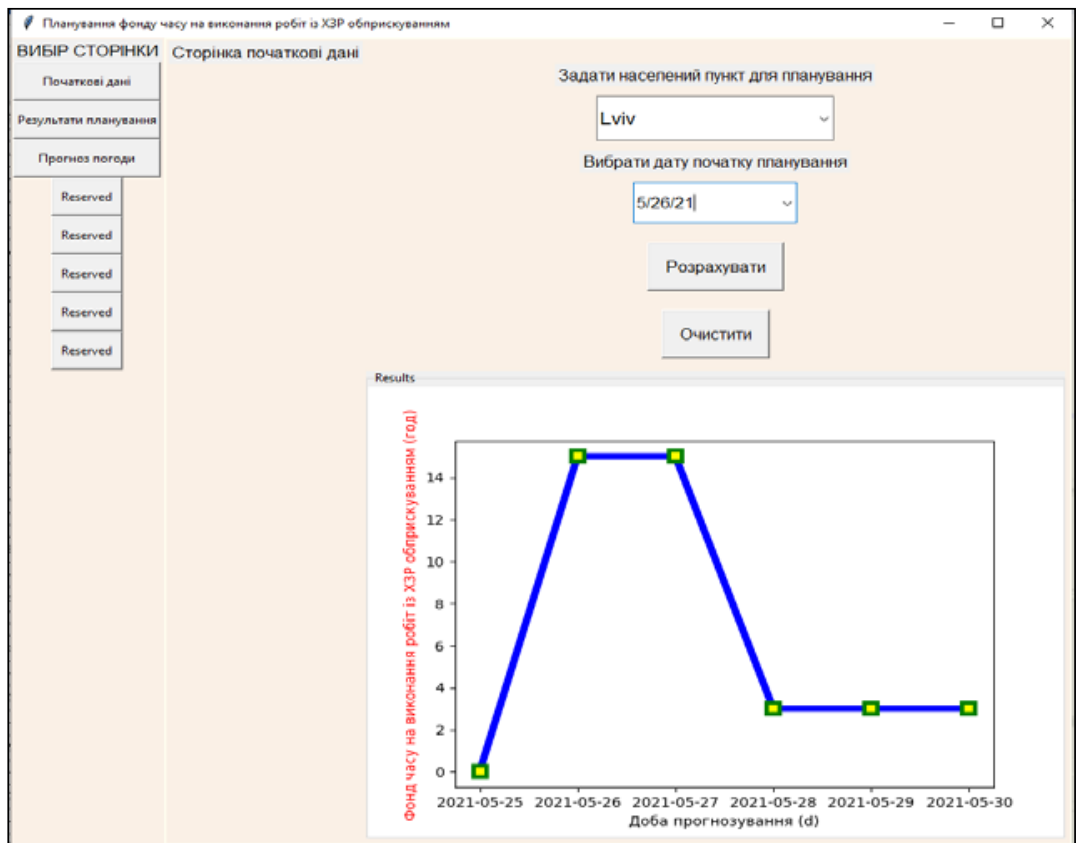

Figure 3: The working window of the intelligent system of support of decision-making of management during forecasting of time fund for the performance of the mechanized chemical protection of plants in a separate day

The probability of favorable conditions for chemical plant protection is greatest in the morning and evening. In view of this, it is advisable to divide the work into half shifts (3 hours in the morning and 3 hours in the evening). The half-shift duration is set in hours (the default half-shift duration is 3 hours).

Developed intelligent management decision support system for forecasting the time fund for mechanized chemical plant protection performs the necessary calculations and provides determination and visualization of climatically acceptable time fund for mechanized chemical plant protection by spraying on a single day for a given country and its region. The 
DOI: 10.14807/ijmp.v12i6.1782

proposed intelligent management decision support system was tested for adequacy according to the Mann-Whitney test for the conditions of the Lviv United Territorial Community (Ukraine). The deviation of the values of the projected time fund for the implementation of mechanized chemical protection of plants from the actual values did not exceed $4 \%$, which confirms the adequacy.

Based on the use of the developed intelligent management decision support system for forecasting the time fund, computer modeling of the agrometeorological component for different days of the mechanized chemical plant protection season for the conditions of the Western Forest-Steppe of Ukraine was carried out.

The conducted researches provided construction of the histogram and a theoretical curve of distribution of the climatically admissible fund of time for the mechanized chemical protection of plants during days for May.

Statistical processing of the obtained data on the climatically acceptable time fund for mechanized chemical protection of plants during the day $\left(t_{d}\right)$ allowed to determine the numerical characteristics, as well as to substantiate the model (Fig. 3), which is described by the Weibull distribution with differential function

$$
f\left(t_{d}\right)=0,332\left(\frac{t_{d}-1}{4,94}\right)^{0,64} \times \exp \left[-\left(\frac{t_{d}-1}{4,94}\right)^{1,64}\right] .
$$

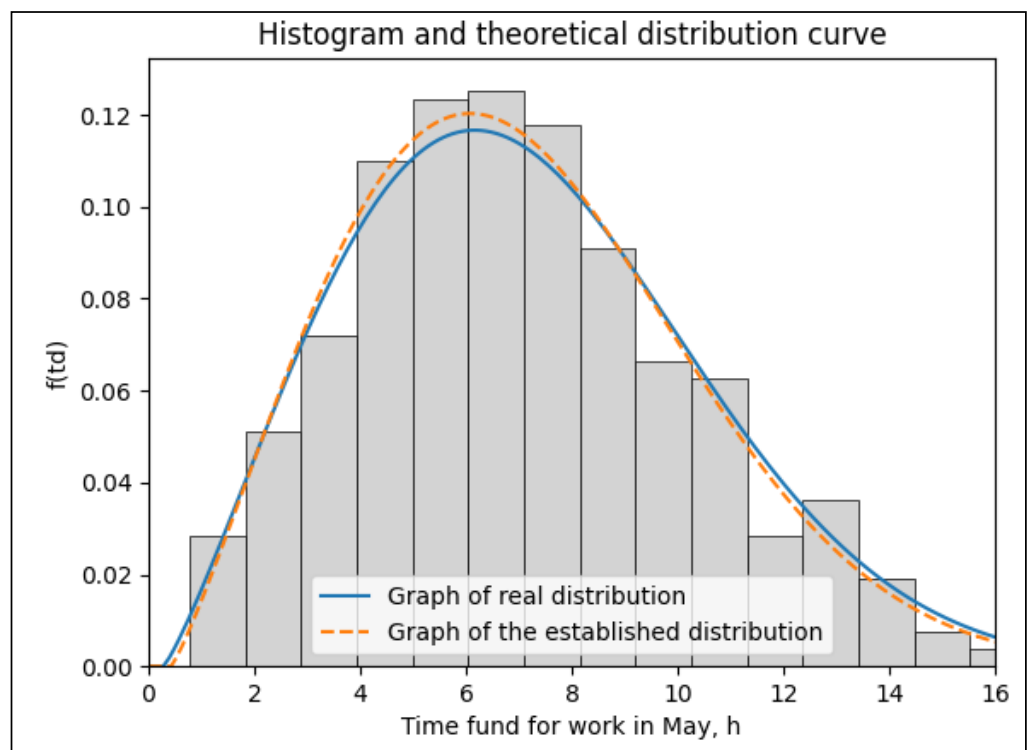

Figure 4: Model of climatically acceptable time fund for mechanized chemical protection of plants during the day in May 
The main statistical characteristics of the distribution of climatically acceptable time fund for mechanized chemical protection of plants during the day in May are as follows: estimation of mathematical expectation - 8.9 hours; dispersion - 11.0 hours; estimation of the standard deviation -3.33 hours.

The test for the adequacy of the theoretical distribution of the climatically permissible fund of time for mechanized chemical plant protection with empirical data was carried out according to the $\chi^{2}$-Pearson criterion.

A well-grounded approach to forecasting the time fund for mechanized chemical plant protection and based on it developed algorithm and intelligent management decision support system provide quality forecasting of time fund for mechanized chemical plant protection taking into account the agrometeorological component of individual countries and their regions.

\section{CONCLUSIONS}

The proposed approach, algorithm, and intelligent management decision support system for forecasting the time fund for mechanized chemical plant protection are based on the formation of a database and knowledge of weather from the OpenWeatherMap service for individual countries and their regions. The main feature of the proposed approach is that the formation of databases and knowledge is performed for a given country or region, taking into account the characteristics of climatic and industrial conditions based on computer modelling, which provides systematically considered many variable agrometeorological components of mechanized chemical plant protection and their impact on the projected time fund of the relevant works. This fully takes into account the specifics of the subject area, provides quality database and knowledge, as well as the creation of an intelligent system that provides rapid and high-quality management decisions on forecasting the time to perform mechanized chemical plant protection.

On the basis of the use of the developed intelligent system of support of acceptance of administrative decisions forecasting of time fund for the performance of the mechanized chemical protection of plants and the set natural-climatic and industrial conditions is executed. This provided substantiation of the model of climatically acceptable time fund for mechanized chemical protection of plants during the day in May, which is described by the Weibull distribution with the main statistical characteristics: estimation of mathematical expectation 8.9 hours; dispersion - 11.0 hours; estimation of the standard deviation -3.33 hours. The 
INDEPENDENT JOURNAL OF MANAGEMENT \& PRODUCTION (IJM\&P)

http://www.ijmp.jor.br

v. 12, n. 6, Special Edition ISE, S\&P - November 2021

ISSN: 2236-269X

DOI: $10.14807 /$ ijmp.v12i6.1782

obtained research results can be used by managers of agricultural enterprises during the management processes of forecasting the time fund for the implementation of mechanized chemical plant protection.

\section{REFERENCES}

Bashynsky, O. (2019). Coordination of dairy workshops projects on the community territory and their project environment. In: 14-th International Scientific and Technical Conference on Computer Sciences and Information Technologies. Lviv Polytechnic National University, 17-20 September. Lviv, 51-54.

Bazzaz, F., \& Sombroek, W. (1996). Global climate change and agricultural production: direct and indirect effects of changing hydrological soil and plant physiological processes.

FAO, Rome, Italy. Available at:

http://www.fao.org/docrep/w5183e/w5183e00.htm\#Contents.

Boyarchuk, V., Boyarchuk, V. \& Ftoma, O. (2019). Evaluation of risk value of investors of projects for the creation of crop protection of family dairy farms. Acta Universitatis Agriculturae et Silviculturae Mendelianae Brunensis, 67(5), 1357-1367.

Boyarchuk, V. \& Ftoma, O. (2019). Forecasting of a lifecycle of the projects of production of biofuel raw materials with consideration of risks. International Conference on Advanced Trends in Information Theory (ATIT), pp. 420-425.

Boyarchuk, V., Ftoma, O., Francik, S., \& Rudynets, M. (2020). Method and software of planning of the substantial risks in the projects of production of raw material for biofuel. In: International Workshop IT Project Management. Ukrainian Project Management Association "UKRNET” \& Lviv Polytechnic National University, 18-20 February. Slavsko, pp. 116-129.

Boychenko, S., \& Voloshchuk, V. (2007). The stochastic semi-empirical model of spacetemporal transformation of the modern climate of Ukraine. National Academy of Science of Ukraine, 1,105-109.

Fraisse, C. W., Breuer, N. E., Zierden, D., Bellow, J. G., Paz, J., Cabrera, V. E., ... O'brien, J. J. (2006). AgClimate: a climate forecast information system for agricultural risk management in the southeastern USA. Computers and Electronics in Agriculture, 53(1), $13-27$.

Hulida, E., Pasnak I., \& Koval, O. (2019). Determination of the Critical Time of Fire in the Building and Ensure Successful Evacuation of People. Periodica Polytechnica Civil Engineering, 63(1), 308-316.

Islam, S., \& Mandal, W. A. (2017). A fuzzy inventory model (EOQ model) with unit production cost, time depended holding cost, without shortages under a space constraint: a fuzzy parametric geometric programming (FPGP) approach. Independent Journal of Management \& Production, 8(2), 299-318. DOI: 10.14807/ijmp.v8i2.535.

Ljaskovska, S., Martyn, Y., Malets, I., \& Prydatko, O. (2018). Information technology of process modeling in the multiparameter systems. In: II International Conference on Data Stream Mining and Processing. Lviv Polytechnic National University, 21-25 August. Lviv, pp. 177-182.

Lobell, D., \& Field, C. (2007). Global scale climate-crop yield relationships and the impacts of recent warming. Environ. Res. Lett., 2, 1-7. 
Nuzhna O., Tluchkevych N., Semenyshena N., Nahirska K., \& Sadovska I. (2019). Making managerial decisions in the agrarian management through the use of ABC-Analysis tool. Independent Journal of Management \& Production, 10(7), 798-816. DOI: http://dx.doi.org/10.14807/ijmp.v10i7.901.

Pavlikha, N., Rudynets, M., Grabovets, V., Skalyga, M., Tsymbaliuk, I., Khomiuk, N., \& Fedorchuk-Moroz, V. (2019). Studying the influence of production conditions on the content of operations in logistic systems of milk collection. Eastern-European Journal of Enterprise Technologies: Control processes, 99(3/3), 50-63.

Ratushny, R., Bashynsky, O., \& Ptashnyk, V. (2019). Development and usage of a computer model of evaluating the scenarios of projects for the creation of firefighting systems of rural communities. In: XI-th International Scientific and Practical Conference on Electronics and Information Technologies. Ivan Franko National University of Lviv, 16-18 September. Lviv, 34-39.

Ratushny, R., Bashynsky, O. \& Shcherbachenko, O. (2018). Identification of firefighting system configuration of rural settlements Fire and Environmental Safety Engineering.

MATEC Web Conf (FESE 2018), 247. DOI:

https://doi.org/10.1051/matecconf/201824700035.

Ratushnyi, R., Khmel, P., Martyn, E., \& Prydatko, O. (2019). Substantiating the effectiveness of projects for the construction of dual systems of fire suppression. Eastern-European Journal of Enterprise Technologies: Control processes, 100(4/3), 46-53.

Roy, P. C., Guber, A., Abouali, M., Pouyan Nejadhashemi, A., Deb, K., \& Smucker, A. (2019). Crop yield simulation optimization using precision irrigation and subsurface water retention technology. Environmental Modelling \& Software, 119, 433-444.

Serrano, I. V., Gonzalez-Hidalgo, S. M., De Luis, J. C., \& Raventos, M. J. (2004). Drought patterns in the Mediterranean area: the Valencia region (eastern Spain). Climate Research, 26, 5-15.

Sokulskyi, O., Hilevska, K., Chumakevych, V., Ptashnyk, V., \& Sachenko, A. (2020). The Internet of Things Solutions in the Investigation of Urban Passenger Traffic and Passenger Service Quality. IEEE European Technology and Engineering Management Summit (ETEMS). DOI: 10.1109/E-TEMS46250.2020.9111658.

Syrotiuk, V., Syrotiuk, S., Ptashnyk, V., Baranovych, S., Gielzecki, J., \& Jakubowski, T. (2020). A hybrid system with intelligent control for the processes of resource and energy supply of a greenhouse complex with application of energy renewable sources. Przegląd elektrotechniczny, 96(7), 149-152.

Tryhuba, A., Bashynskyi, O., Medvediev, Y., Slobodian, S., \& Skorobogatov, D. (2019). Justification of models of changing project environment for harvesting grain, oilseed and legume crops. Independent Journal of Management \& Production, 10(7), 658-672.

Tryhuba, A., Boyarchuk, V., Tryhuba, I., Ftoma, O., Padyuka, R., \& Rudynets, M. (2019). Forecasting the Risk of the Resource Demand for Dairy Farms Basing on Machine Learning. Proceedings of the 2nd International Workshop on Modern Machine Learning Technologies and Data Science (MoMLeT+DS 2020), I, 327-340.

Tryhuba, A., Hridin, O., Slavina, N., Mushenyk, I., \& Dobrovolska, E. (2020). Managerial decisions in logistic systems of milk provision on variable production conditions.

Independent Journal of Management \& Production, 11(8), 783-800. 
Tryhuba, A., Hutsol, T., Glowacki, S., Tryhuba, I., Tabor, S., Kwaśniewski, D., Sorokin, D., \& Yermakov, S. (2021). Forecasting Quantitative Risk Indicators of Investors in Projects of Biohydrogen Production from Agricultural Raw Materials. Processes, 9(2), 258. DOI: https://doi.org/10.3390/pr9020258.

Tryhuba, A., Ivanyshyn, V., Chaban, V., Mushenyk, I., \& Zharikova, O. (2021). Influence of agrometeorological component of the project environment on the duration of works in chemical protection projects of agricultural crops. Independent Journal of Management \& Production (Special Edition ISE, S\&P), 12(3), 138-149. DOI:

https://doi.org/10.14807/ijmp.v12i3.1531.

Tryhuba, A., Tryhuba, I., Mushenyk, I., Pashchenko, O., \& Likhter, M. (2020). Computer model of resource demand planning for dairy farms. Independent Journal of Management \& Production, 11(9), 658-672. DOI: https://doi.org/10.14807/ijmp.v11i9.1410. 